\title{
Effect of Creatine on Rat Sciatic Nerve Injury: A Comparative Ultrastructural Study
}

\author{
Fatma HELVACIOGLU', Ersin KANDEMIR², Busra KARABACAK², Idil KARATAS ${ }^{2}$, Ahmet PECEN², Ipek ERCAN², \\ Tugce SENCELIKEL ${ }^{3}$, Attila DAGDEVIREN ${ }^{1}$
}

\author{
${ }^{1}$ Baskent University, Medical School, Department of Histology and Embryology, Ankara, Turkey \\ ${ }^{2}$ Baskent University, Medical School, Phase III Student, Ankara, Turkey \\ ${ }^{3}$ Baskent University, Medical School, Department of Biostatistics, Ankara, Turkey
}

\section{ABSTRACT}

AIM: Creatine is an endogenous molecule synthesized in the liver, kidney and pancreas from glycine and arginine and is important for mitochondrial metabolism. It is widely used as a supplement for improving muscle mass and function for many years. As it is expected to prevent apoptosis and diminish oxidative stress, it is also studied in a number of neurodegenerative diseases for its beneficial effect in recent years. We studied the effect of creatine on the peripheral nerve injury in an experimental rat crush injury model to obtain ultrastructural evidence.

MATERIAL and METHODS: Animals were randomly divided into 3 groups having 5 animals in each group. Group 1 was the control group, Group 2 the trauma group and Group 3 the trauma+creatine group. The first group served as sham control. In group 2 and group 3, sciatic nerves of the rats received crush injury using aneurysm clips. In group 3, daily 2 g/kg creatine monohydrate was administered via gavage after the trauma. Nerve samples were obtained at the $28^{\text {th }}$ day after trauma for light and electron microscopic evaluation.

RESULTS: Our comparative analysis results suggest a possible positive effect of creatine supplement on peripheral nerve regeneration as statistical analysis revealed significant differences between group 2 and group 3 . Though our finding does not represent a miracle of regenerative support, beneficial usage of creatine is documented in the present study.

CONCLUSION: Creatine supplement helps to diminish the harmful effects of peripheral nerve crush injury which is also supported by electron microscopy findings.

KEYWORDS: Sciatic nerve injury, Creatine, Electron microscope

\section{INTRODUCTION}

$\mathrm{I}$ $t$ is generally accepted that regenerative capacity of the nervous system is rather restricted especially in the central nervous system (CNS). However, peripheral nerves have a limited capacity of axonal regeneration if the neuron survives following Wallerian degeneration as well documented $(20,28,33,35,38,39)$. Regarding these data, many investigators have tried to determine factors to facilitate the regeneration process including microsurgical aids, laser therapy, admin- istration of various substances and supporting the overall healthy state of the organism $(11,17,18,33,40)$. Oxidative stress and inflammatory changes occurring at the site of and distal to injury are major factors affecting the fate of regeneration process as well documented by a number of studies $(7,9,12-14,21,24,27,34)$. Researchers were also focused on preventing harmful effects of oxidative stress using anti-oxidant agents like melatonin (17), alpha-lipoic acid (23), epigallocatechin gallate (EGCG) (40), and some others. Creatine is an endogenous molecule that is closely related to the energy 
metabolism, and it is widely used as a supplement for increasing muscle mass during bodybuilding and to increase the performance of athletes $(10,22,32,37)$. Because of its function in energy metabolism, researchers also studied the preventive effect of creatine in a number of neurodegenerative diseases in recent years $(1-3,5,8,16,26,29)$.

However, we could not find a report on the effect of creatine in peripheral nerve regeneration in the literature. Thus we planned to study the effect of creatine monohydrate in the recovery process of the rat sciatic nerve following crush injury. We used an image analysis program for the light microscopic measurements for comparative evaluation. We also examined samples from sciatic nerves 28 days after crush injury for ultrastructural comparison.

\section{MATERIAL and METHODS}

The study was performed in 15 healthy, 6-month-old adult male Wistar albino rats, weighing 200-250 g. Animals, which were exposed to 12-hours of light and 12-hours of dark cycle, were kept in a standard laboratory cage and sufficient chow food and water were provided at $18-21^{\circ} \mathrm{C}$. The study guidelines and experimental protocol were approved by Ethical Committee of Baskent University Faculty of Medicine (Decision No: DA16/16) and all experimental procedures were performed at the Animal Laboratory of the same faculty.

\section{Power Analysis}

"A priori" power analysis was performed by using statistical program $G^{*} P o w e r$ to determine the required sample size for one-way analysis of variance. The sample size was calculated as 15 rats ( 5 rats for each group) in total which produced $80 \%$ power with partial $\eta^{2}=0.50$ at $5 \%$ significance level.

\section{Groups}

Animals were randomly divided into 3 groups having 5 animals each:

i) Control group

ii) Trauma group

iii) Trauma+2 g/kg creatine monohydrate (Sigma C3630) group.

The first (control) group served as sham control. In the trauma group, sciatic nerves of the rats received compressioninduced (crush) injury using clips with a pressure of $50 \mathrm{gr} /$ $\mathrm{cm}^{2}$ for 1 minute. In the third group, daily $2 \mathrm{~g} / \mathrm{kg}$ (23) creatine monohydrate in tap water was administered via gavage following the trauma, as described for group 2, for 28 days.

\section{Anesthesia and Surgical Procedure}

The rats, which were left hungry for one night, were weighed, and anaesthetized with Xylazine (Rompun ${ }^{\circledR}, 2 \%$ solution, Bayer) $7 \mathrm{mg} / \mathrm{kg}$ and Ketamine Hydrochloride (Ketalar ${ }^{\circledast}, 5 \%$ solution, Parke Davis-EWL) $70 \mathrm{mg} / \mathrm{kg}$ and Fentanyl ${ }^{\circledR}$ (JanssenCilag) $(0.01 \mathrm{mg} / \mathrm{kg})$ intraperitoneally prior to surgery. Rats were placed in the prone position and the sciatic nerve, lying under the gluteus maximus muscle, was explored through a longitudinal skin incision, at the level of the greater trochanter, proximal to the right lower extremity, and dissected by avoiding tractional damage. Neural injury was produced by compression of the sciatic nerve of each rat for 1 minute using an aneurysm clip (Yasargil FE 693 temporary aneurysm clip, Aesculap) with a closing pressure of $50 \mathrm{~g} / \mathrm{cm}^{2}$ for axonotmesis. Then, the incision was closed anatomically. All operated animals received Baytril- $K^{\circledast}$ (Enrofloxacin, 5\% solution, Bayer) $5 \mathrm{mg} / \mathrm{kg}$ to prevent postoperative infection. Four weeks later, all rats were deeply anesthesized (Ketamine hydrochloride $150 \mathrm{mg} / \mathrm{kg}$ ) and specimens of the damaged sciatic nerves, including $0.5 \mathrm{~cm}$ proximal and distal nerve segments, were collected from the prior incision sites. At the end of the study, the rats were sacrificed (40).

\section{Electron Microscopy}

Tissues were fixed in phosphate buffered $(\mathrm{pH}=7.3)$ containing $2.5 \%$ Glutaraldehyde (Sigma-Aldrich Co.) for 2 hours at room temperature, post-fixed in 1\% Osmium tetroxide (SigmaAldrich Co.) and dehydrated in a series of graded alcohols. After passing through Propylene oxide (Sigma-Aldrich Co.), the specimens were embedded in Araldite CY 212 (CibaGeigy), (2-dodecen-1-yl) Succinic anhydride 95\% (SigmaAldrich Co.), Benzyldimethyl amine (Poly Sciences Inc.) and Dibutylphtalate (Sigma-Aldrich Co.). The semi-thin sections obtained from plastic-embedded blocks were stained with $1 \%$ Toluidine blue (Sigma-Aldrich Co.) and examined with a light microscope (Leica DM3000, Germany). Digital images were obtained using a digital camera (Leica DM 500, Germany) and captured images were processed and analyzed using TT2D-BIAS software developed by our faculty (25). Thin sections of the samples from each group were cut using an ultramicrotome (Leica Ultracut R, Germany); stained with Uranyl acetate (ProSciTech) and Lead citrate (Sigma-Aldrich Co.) and examined and photographed by electron microscope (Leo 906 E Carl Zeiss, Germany).

\section{Histomorphometric Analysis}

We quantified the areas of myelin and axon respectively and calculated the g-ratio values in semi-thin transverse sciatic nerve sections. For the randomly selected quantification analysis to obtain G-ratios, digital images taken at X1000 magnification were used. For the determination of vascular area measurements and ondulated/indented fragmentation, entire nerve sections were examined for each animal. The G-ratio of each sample was obtained by the division of the inner axonal diameter to the outer fiber diameter, and the results were classified for $G$ ratio ranges of $0.41-0.54,0.55-$ 0.68 , and $0.69-0.9$. While grouping into ranges, the values were evaluated using the last 2 digit values and upon this value group to upper or lower range.

\section{Statistical Method}

Statistical analysis was performed using the "Statistical Package for Social Sciences (SPSS) v17.0" (SPSS for Windows version 17.0, Chicago, IL, USA-September 2012 license number: 1093910, Baskent University). Descriptive statistics were reported, including mean, standard deviation, median, minimum value, maximum value. For the continuous 
dependent variables, One Way Analysis of Variance or Kruskal-Wallis test was used for comparisons between 3 groups (Control, Trauma and Trauma+Creatine), depending on whether the dependent variable follows a normal distribution within the groups. The association between G-ratio and group was investigated by Cramers' V correlation coefficient. For the categorical dependent variables Pearson Chi-Squared test was used for testing the independence. The probability of a Type I error (alpha) was chosen as 5\% (two-tailed) in all tests.

\section{RESULTS}

\section{Light Microscopy}

In the light microscopic examination of sciatic nerve cross sections of the control group, axons, myelin sheath and interstitial compartments all appeared normal with the exception of a very few myelin sheath indentations and slight separation areas. Several sections of blood vessels were also present in all sections (Figure 1).

In the trauma group samples, we observed many fibers having degenerative changes of the myelin coat. Disintegrated myelin fragments sometimes covered normal fiber sections areas, obscuring their structure. Relatively few numbers of nerve fibers with a normal and thin myelin coat were also present among degenerated fiber groups. Distinct vacuolar degeneration was also evident in the Schwann cells' cytoplasm. A relative increase in the fibrous components of interstitial tissue was also observed (Figure 2).

In the trauma and creatine-administered group samples, we observed many small diameters and thin myelinated fibers. Schwann cells' cytoplasm with vacuolar degeneration and mast cells were seen in some areas. Blood vessels were also seen in this group (Figure 3 ).

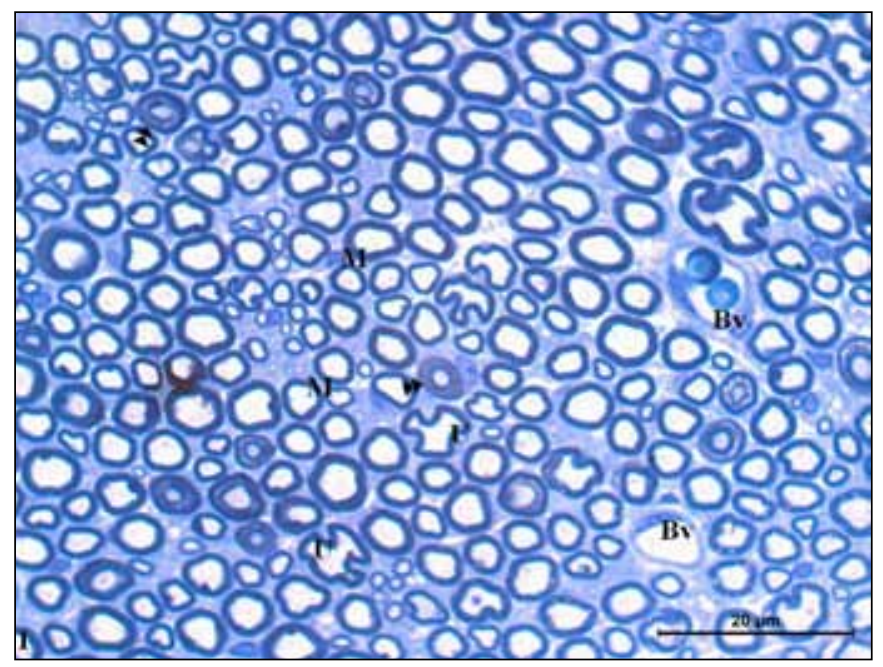

Figure 1: Photomicrograph of an area in sciatic nerve belonging to sham group: M; normal myelinated nerve fibers, $\gg$; duplication of myelin coat, U: Undulation, Bv; Blood vessel (Toluidine blue $\mathrm{X} 1000)$.

\section{Light Microscopic Measurements for Statistical Comparison}

For the measurements to perform statistical analysis, we used the entire cross-sections of sciatic nerves and each nerve was examined according to the mesh system illustrated in (Figure 4). Measurements were performed on the digital images of nerves under X1000 magnification using TT2DBIAS software. G-ratios were then calculated using the obtained values and summarized in Table I. For the rat sciatic nerve, 0.55-0.68 G-ratio was generally accepted in normal range (15). The number of the fibers in normal range was significantly higher in the Control group when compared to

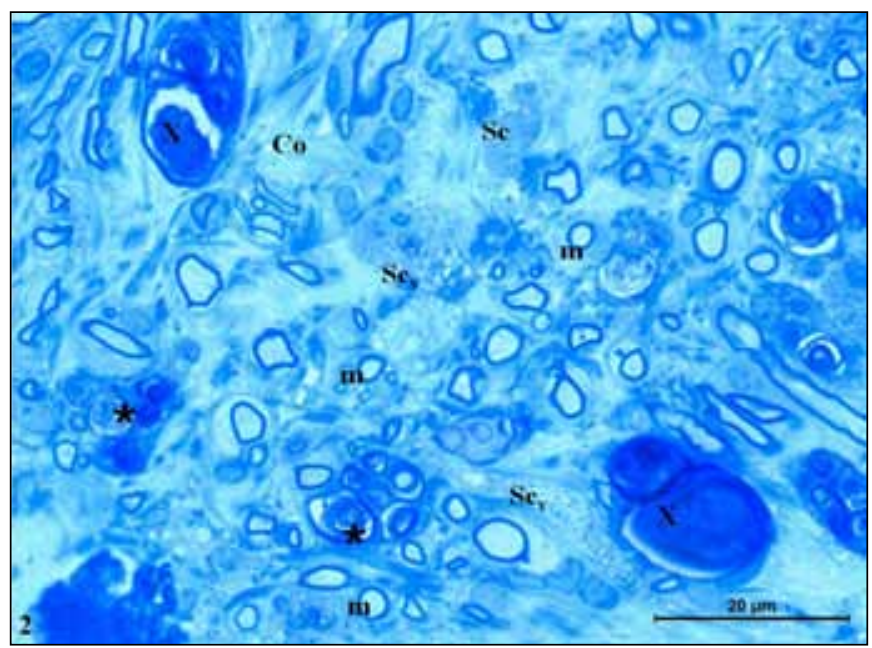

Figure 2: Photomicrograph of an area in sciatic nerve belonging to trauma group: $\mathrm{m}$; thin myelinated nerve fibers, $\mathrm{X}$; extensive myelin degeneration, $\star$; myelin figures in macrophage, $\mathrm{Sc}_{\mathrm{v}}$; Schwann cell having vacuolar degeneration, Co; collagen fibers (Toluidin blue X1000).

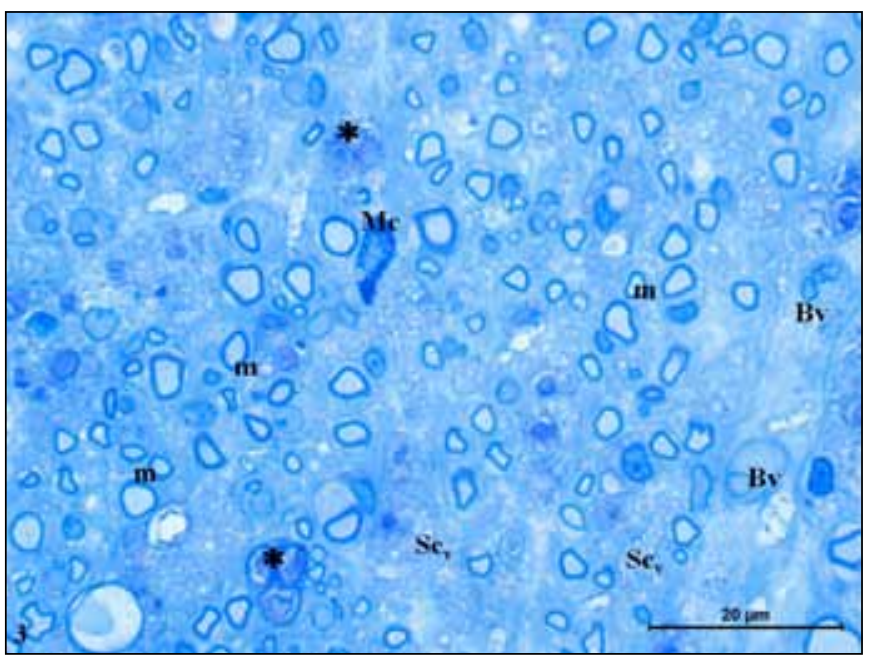

Figure 3: Photomicrograph of an area in sciatic nerve belonging to trauma+ creatine group: $\mathrm{m}$; thin myelinated nerve fibers, $\mathrm{Sc}_{\mathrm{v}}$; Schwann cell having vacuolar degeneration, Mc; mast cell, $\star$; myelin figures in macrophage, Bv; Blood vessel (Toluidine blue X1000). 
Experiment groups (Groups 2 and 3). The number of fibers within the optimal range was significantly increased in the Trauma+Creatine group (Group 3) when compared to the Trauma group. A statistically significant association between G-ratio and group, a somewhat moderate association, was found by Cramer's V correlation coefficient of $0.399(p<0.001)$ (Figure 5). Secondly, we examined the number of vasculature in each nerve section and the number of blood vessels was found to have increased in Group 3 (Trauma+Creatine group) when compared to the others $(p<0.001)$ (Table II, Figure 6). The number of fibers with undulating myelin coat was also determined for the entire cross-sections of all samples for comparison as this finding could be regarded as the mildest degenerative change following injury. The number of fibers with undulated myelin coat in the Trauma group (Group 2) was significantly higher when compared to the other two groups $(\mathrm{p}<0.001)$ (Table II). Additionally, the number of such fibers in Group 3 (Trauma+Creatine group) was significantly lower when compared to the Trauma group ( $p<0.001$ ) (Table II) (Figure 7). Similarly, the number of fibers with fragmented indentations of the myelin coat (which could be referred to as a higher degree of degeneration) was significantly higher in the Trauma group when compared to the other groups $(p<0.05)$ (Table II) (Figure 8). As a final criterion, we compared the mean values of myelin

Table I: G-ratio Analyses among Groups. G-Ratio Optimum Value of the Sciatic Nerve is Accepted in the Range of $0.55-0.68(p<0.001)$

\begin{tabular}{|c|c|c|c|c|}
\hline \multirow{2}{*}{ G-ratio ranges } & \multicolumn{3}{|c|}{ Groups } & \multirow[b]{2}{*}{$\mathbf{p}$} \\
\hline & Control n (\%) & Trauma n (\%) & Trauma+Creatine $\mathrm{n}(\%)$ & \\
\hline $0.41-0.54$ & $5(20.8)$ & $5(20.8)$ & $14(58.3)$ & \multirow{3}{*}{$<0.001$} \\
\hline $0.55-0.68$ & $467(63.7)$ & $59(8)$ & $207(28.2)$ & \\
\hline $0.69-0.69+$ & $27(7)$ & $149(38.9)$ & $207(54)$ & \\
\hline
\end{tabular}

Table II: Quantitative Analysis of Blood Vessels, Undulation, Fragmentation and Myelin Thickness among Groups

\begin{tabular}{|c|c|c|c|c|}
\hline Group & $\begin{array}{l}\text { Blood vessels } \\
\text { Mean } \pm \text { SD }\end{array}$ & $\begin{array}{l}\text { Undulation } \\
\text { Mean } \pm \text { SD }\end{array}$ & $\begin{array}{l}\text { Indented fragmentation } \\
\text { Median (Min-Max) }\end{array}$ & $\begin{array}{l}\text { Myelin thickness } \\
\text { Median (Min-Max) }\end{array}$ \\
\hline Control & $4.20 \pm 0.837^{\mathrm{b}, \mathrm{c}}{ }_{\star \star}$ & $4.20 \pm 1.095^{\mathrm{b}, \mathrm{c}}$ * & $2.00(1-3)^{b}$ * & $0.79(0.38-1.24)^{\mathrm{b}, \mathrm{c}}{ }_{\star \star}$ \\
\hline Trauma & $18.80 \pm 2.387^{\mathrm{a}, \mathrm{c}} \star{ }_{\star \star}$ & $39.20 \pm 5.762^{c}$ * & $38.00(32-42)^{\mathrm{c}}$ & $0.50(0.21-0.84)$ \\
\hline Trauma+Creatine & $22.20 \pm 1.789^{a, b * *}$ & $11.40 \pm 2.510$ & $5.00(3-7)$ & $0.48(0.21-0.91)$ \\
\hline p & $<0.001^{1}$ & $<0.001^{1}$ & $0.002^{2}$ & $<0.001^{2}$ \\
\hline
\end{tabular}

${ }^{*} p<0.05,{ }^{* *} p<0.001$, a: Statistically significant difference when compared with Control, b: Significant difference when compared with Trauma, c: Significant difference when compared with Trauma+Creatine ('ANOVA, ${ }^{2}$ Kruskal-Wallis test).

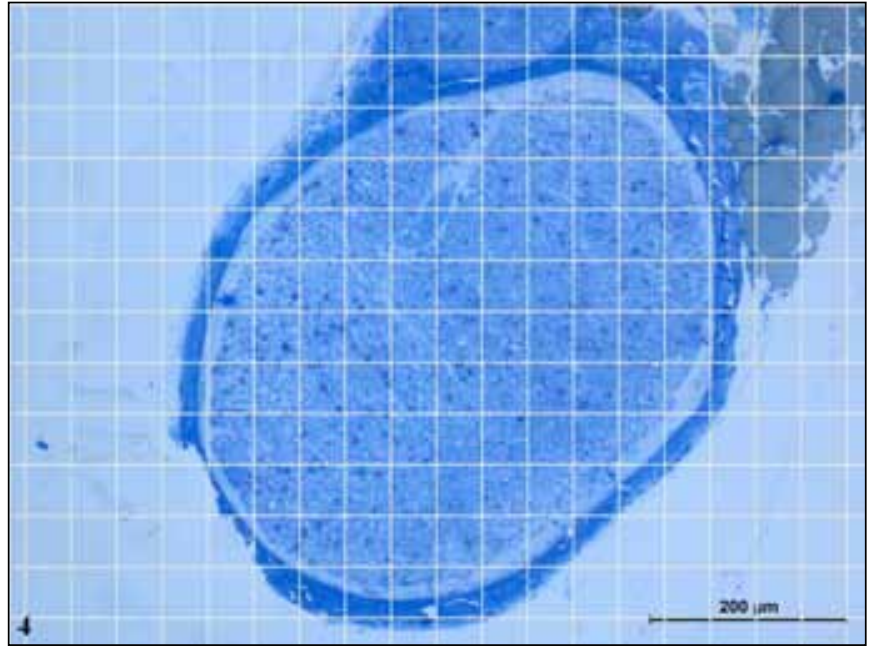

Figure 4: Entire cross-sections of sciatic nerves and each nerve were examined according to the mesh system (Toluidine blue $\mathrm{X} 100)$.

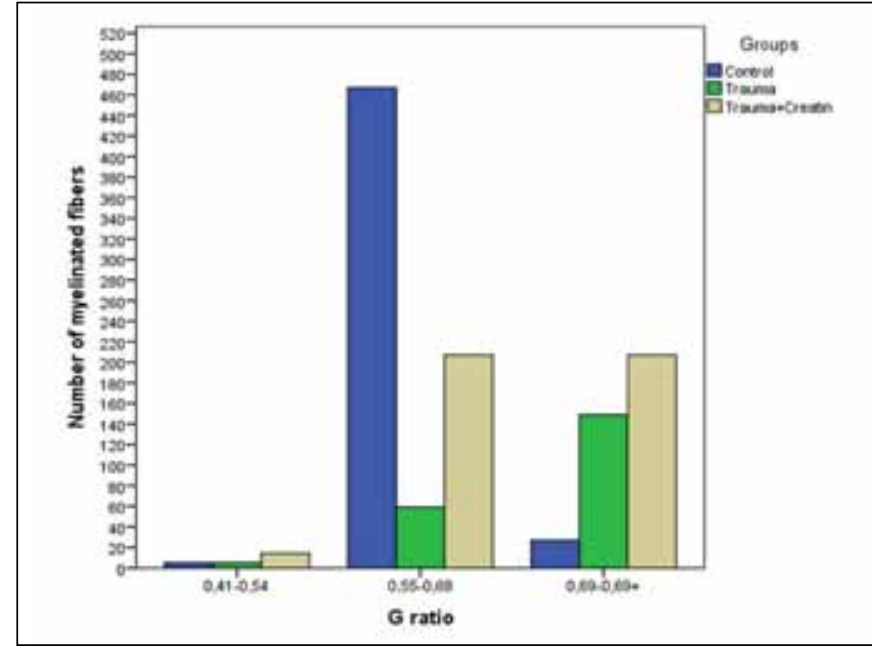

Figure 5: Distribution according to specified intervals of g-ratios among the groups. A statistically significant correlation was present between the G-ratios and groups $(p<0.001)$. 
thickness of fibers in each group. The myelin thickness was higher in the Control group when compared to the other two groups $(p<0.001)$. The myelin thickness was decreased in the Trauma+creatine group when compared to the Trauma group, but this difference was not statistically significant $(p>0.05)$ (Table II, Figure 9).

\section{Electron Microscopy}

Electron microscopic examination of the samples from the Control group revealed the normal structure of myelin coat with Schmidth-Lanterman clefts, Schwann cells and interstitial tissue. Cytoplasmic components of the Schwann cells were all normal (Figures 10,11). A number of distinct degenerative figures were determined in the Trauma group. These were separation of the lamellae, undulation, fragmentation, complete dissolution of the myelin sheath from mildest to most severe changes. Varying degrees of such changes were observed in all the tissue samples. The majority of the fibers exhibited extensive separation of the myelin lamellae, where dissolution also presented in some of them. Collagen con-

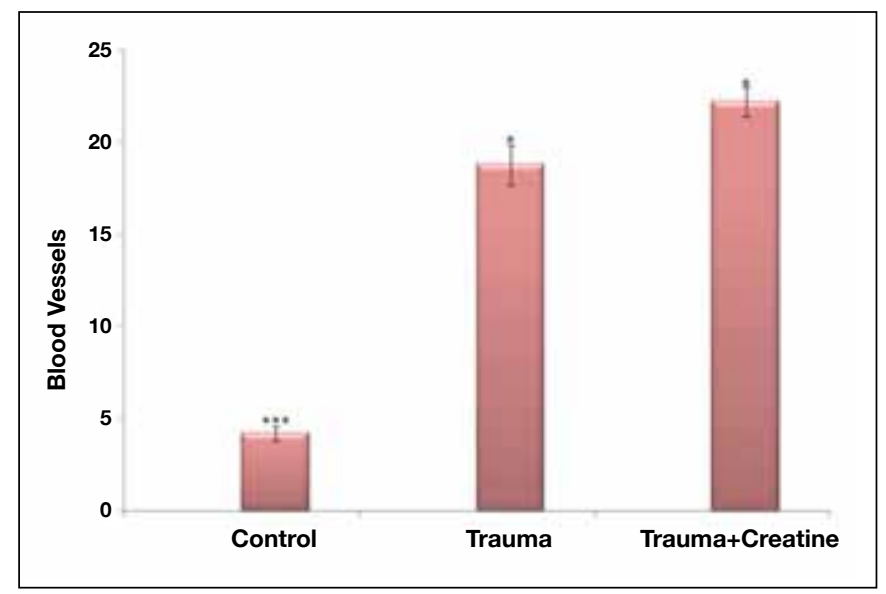

Figure 6: Comparision of the number of blood vessels among the groups $(p<0.001)$.

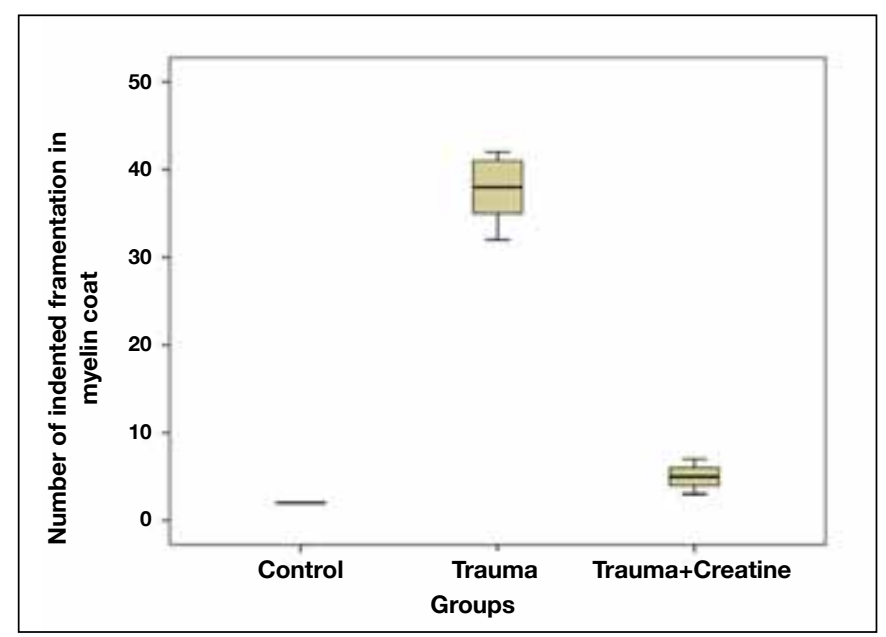

Figure 8: Comparision of the number fibers with indentation myelin coat among the groups $(p=0.002)$. tent of the interstitium was relatively higher when compared to the other two groups (Figure 12). The normal structure of myelin was preserved only in some restricted areas of the coat. In most areas, myelin showed extensive degeneration. In some areas, part of the myelin formed a lobulated, dislamellated degenerative bulb. Separation of the lamellae was also present in the remainder of the coat in this fiber. In the same area, fibers had fragmented myelin mass that appeared to be relatively intact. However, the Schwann cell cytoplasm surrounding this fragment was unusually rich in mitochondria. Disintegration of the myelin lamellae towards the axonal side was also prominent in this fiber and section of a small protrusion of the Schwann cell was also seen in this area (Figure 13). In some areas, large fibers with entirely dissociated myelin coat with no distinct axon section were seen. There were several smaller fibers that gradually appeared normal in structure with the exception of mild ondulations. However, in one of them, lamination (duplication) of the myelin was seen, possibly reflecting the initial stage of the degeneration process. There were also some unmyelinated fibers appearing normal

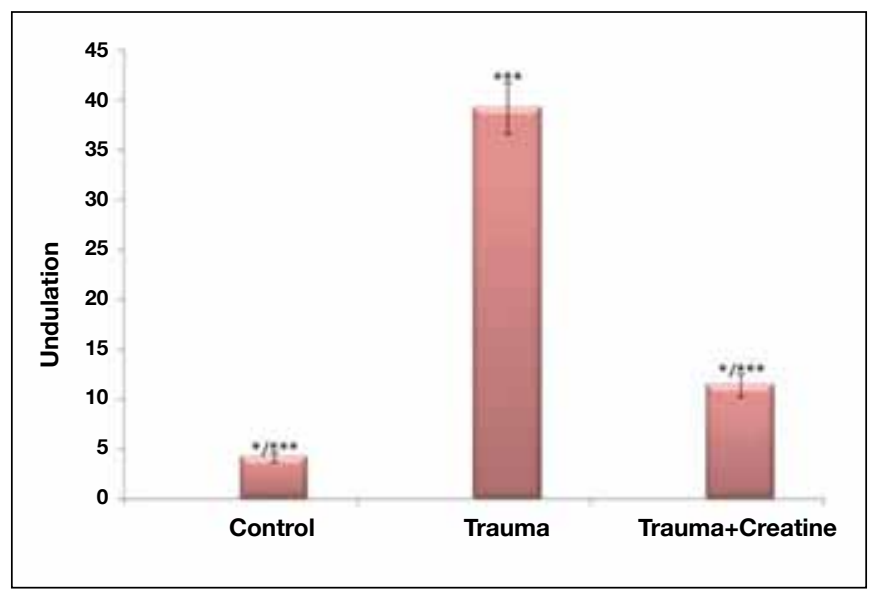

Figure 7: Comparision of the number fibers with undulated myelin coat among the groups $(p<0.001)$.

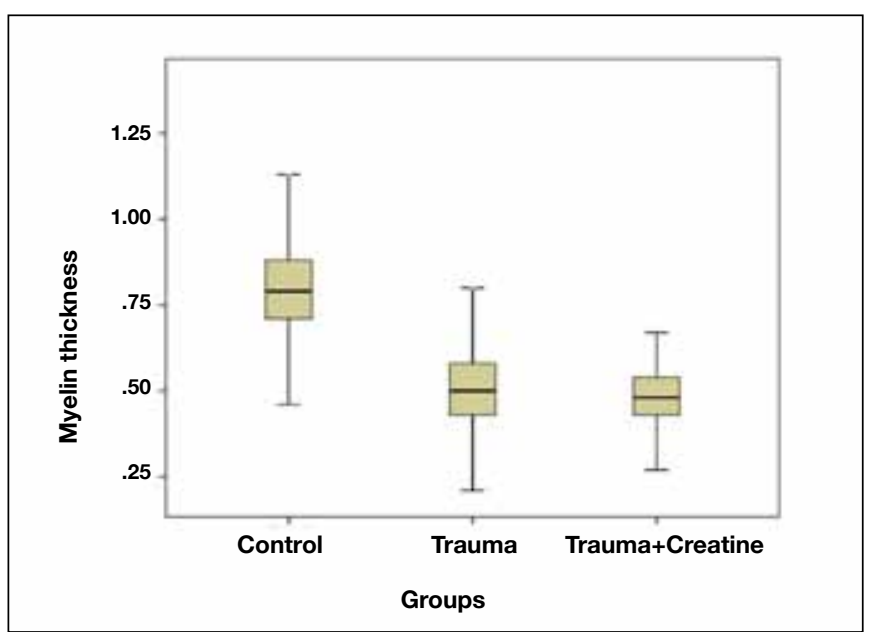

Figure 9: Comparison of the myelin thickness among the groups $(p<0.001)$. 
(Figure 14). In another area in the same group, mast cell and Schwann cell were seen. Schwann cell was organelle-rich with an axon surrounded by a laminated (duplicated) myelin coat. Adjacent to these cells, there was a swollen process of possibly a macrophage with endosomes containing disintegrated myelin figures. The Schwann cell surrounding unmyelinated fibers appeared normal. However, the myelin coat surrounding the normal appearing axon exhibited initial stages of separation extending to the external lamina of the swollen Schwann cell (Figure 15). In the Trauma+creatine group, some of the ultrastructural changes were relatively reversed when compared to the Trauma group. An interesting observation in

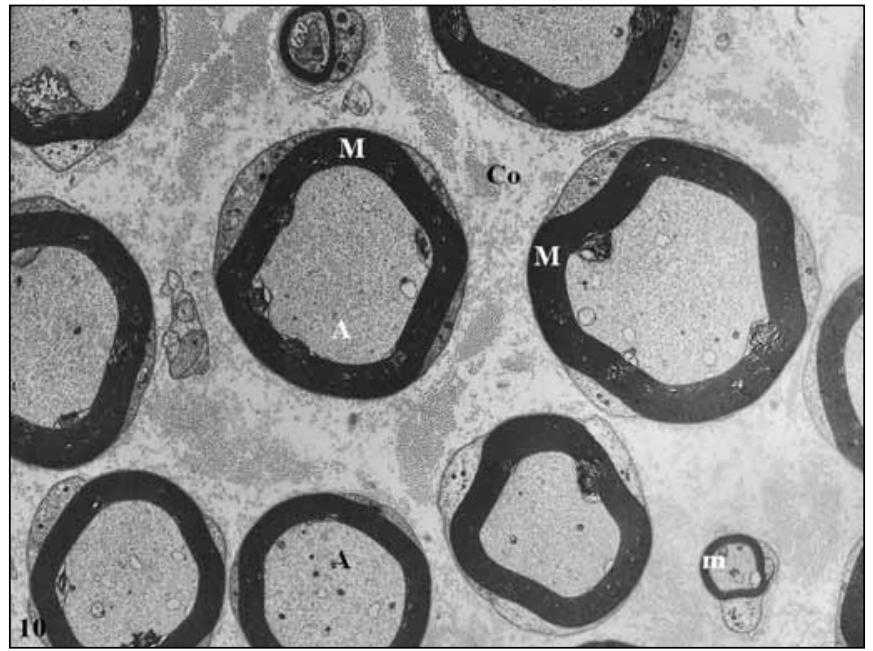

Figure 10: Electron micrograph of nerve fibers from the sciatic nerve of control group. $M$; large myelinated nerve fiber, $\mathrm{m}$; thin myelinated nerve fiber, A; axon, Co; collagen fibers (Uranyl acetate \& Lead citrate, X2784).

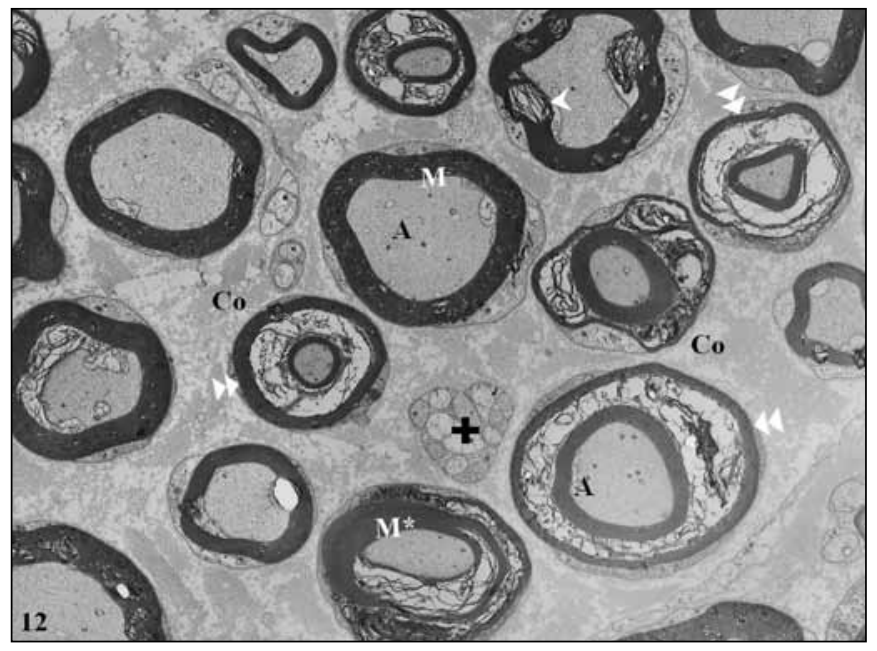

Figure 12: Sciatic nerve section from trauma group. M; myelinated nerve fibers, >; separation of the lamellae, $\gg$; duplication, $M^{\star}$; local disarrangement in myelin coat, A; normal structured axon, +; unmyelinated fibers, Co; collagen fibers (Uranyl acetate \& Lead citrate, X2156). this group was the presence of Schwann cells not associated with nerve fibers, possibly reflecting reactive proliferation of this special cell group. In some fibers, the axons and myelin coat appeared greatly normal but there were few fibers containing vacuoles in the axons. Myelin coats of the fibers were relatively thinner when compared to that of control group and these may therefore represent newly formed ones (Figure 16). At a higher magnification of this group, newly forming myelin coats were observed easier. The areas were rich in unmyelinated fibers. Schwann cells were organelle-rich except some containing few remnants of phagocytic activity. Interesting whirling granular endoplasmic reticulum cistern profiles were

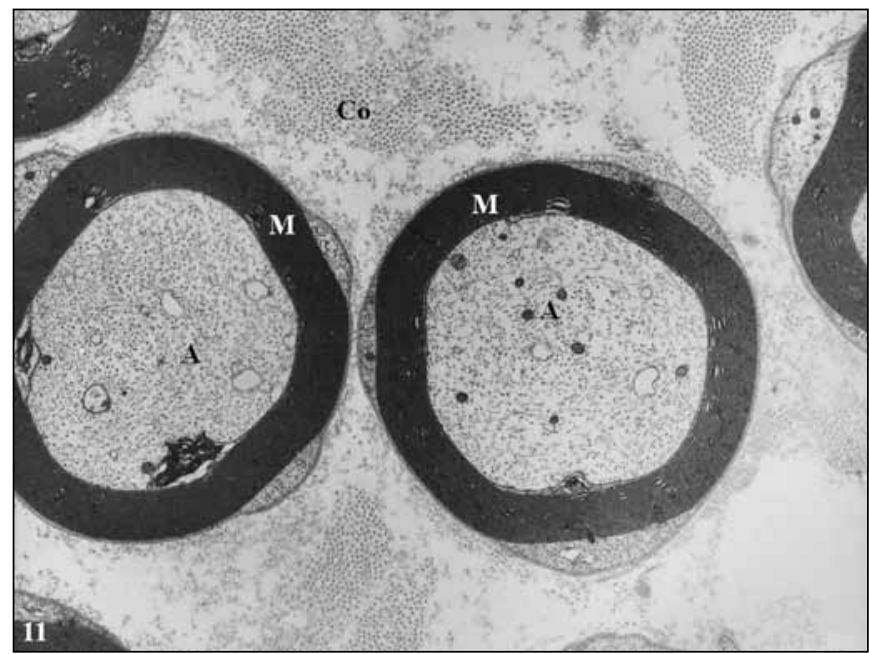

Figure 11: Higher magnification of two nerve fibers reveals the normal architecture of myelin surrounded by neurilemma. $M$; large myelinated nerve fiber, A; axon, Co; collagen fibers (Uranyl acetate \&Lead citrate, X6000).

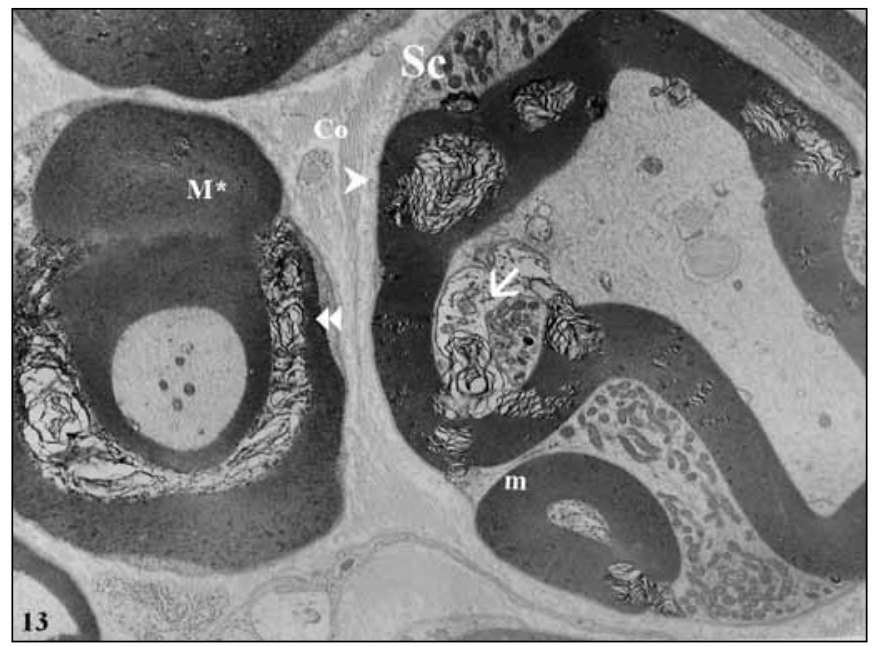

Figure 13: Electron micrograph of two fibers from the trauma group. >; separation of the lamellae, $\gg$; Duplication (where dissolution also present in some of them), $M^{*}$; local disarrangement in myelin coat, m; small myelinated nerve fibers, Sc; Schwann cell, $\rightarrow$; small protrusion of the Schwann cell in axon, Co; collagen fibers (Uranyl acetate\& Lead citrate, X4646). 
observed in another cell's process (Figure 17). In another area, same group signs and reflections of both degeneration/clearing and regeneration were seen in this compartment. Almost totally disintegrated content of phagocytic Schwann cells were present as distinguished by their external lamina. Collagen fiber bundles were relatively extensive when compared to other groups, almost reflecting fibrotic changes. However at the central region, groups of newly myelinated fibers with thin myelin coats were seen. These axons with smaller diameters possibly represent regenerating fibers in this region (Figure 18).

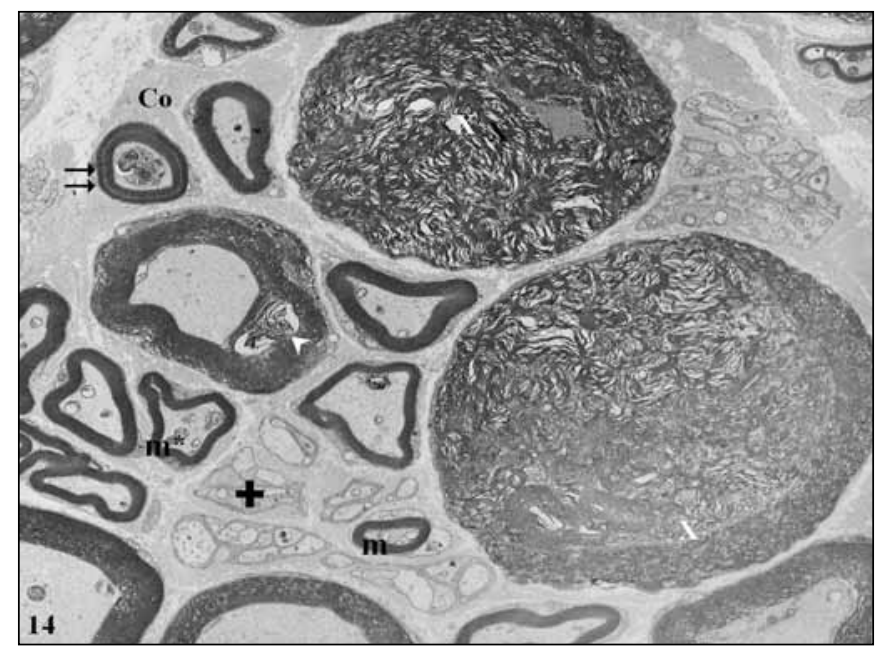

Figure 14: Medium power micrograph of another sample from the trauma group. $\mathrm{m}$; small myelinated nerve fibers, $\mathrm{m}^{*}$; mild undulation, $\rightrightarrows$; lamination (initial stage of degeneration process), X; completely dissociated myelin coat with no distinct axon, +; unmyelinated fibers, Co; collagen fibers, (Uranyl acetate \&Lead citrate, X2784).

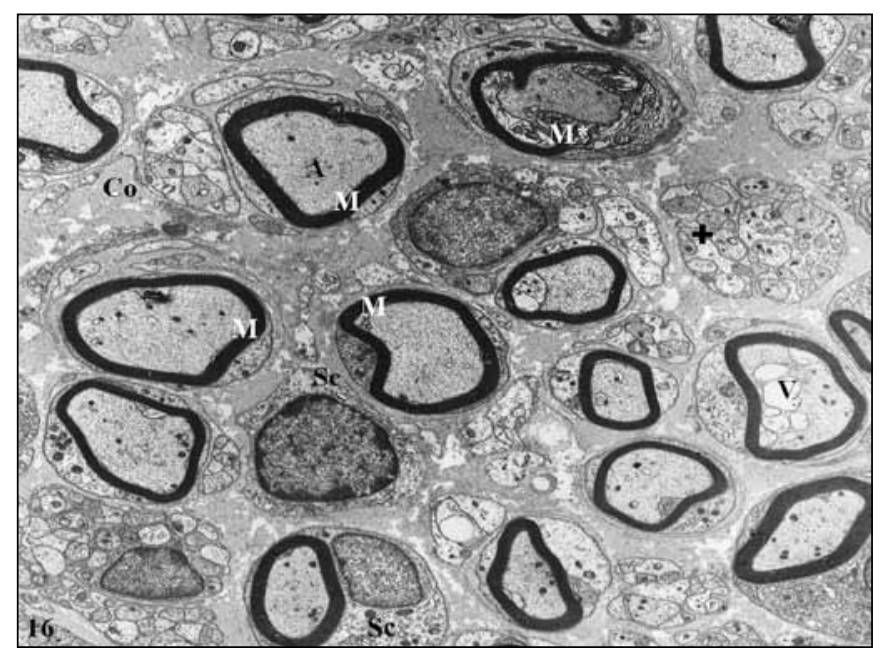

Figure 16: Sciatic nerve section from trauma+creatine group: $M$; myelinated nerve fibers, $M^{*}$ : local disarrangement in myelin coat, A; axon, V; vacuoles, Sc; Schwann cell, +; unmyelinated fibers, Co; collagen fibers (Uranyl acetate \& Lead citrate, X2784).

\section{DISCUSSION}

Peripheral nerve injury and regeneration represent one of the critical topics of interest as they make up a serious clinical problem. In general, it is accepted that regeneration of nervous tissue is rather restricted especially regarding the CNS $(7,14)$. Intensive studies have been carried out to improve regeneration of peripheral nerves as this process is more promising. Several methodical approaches were considered to support the regenerative capacity of Schwann cells and neurons using the data from basic research. Among these approaches, genetic mutation and/or knock-out studies, administration of

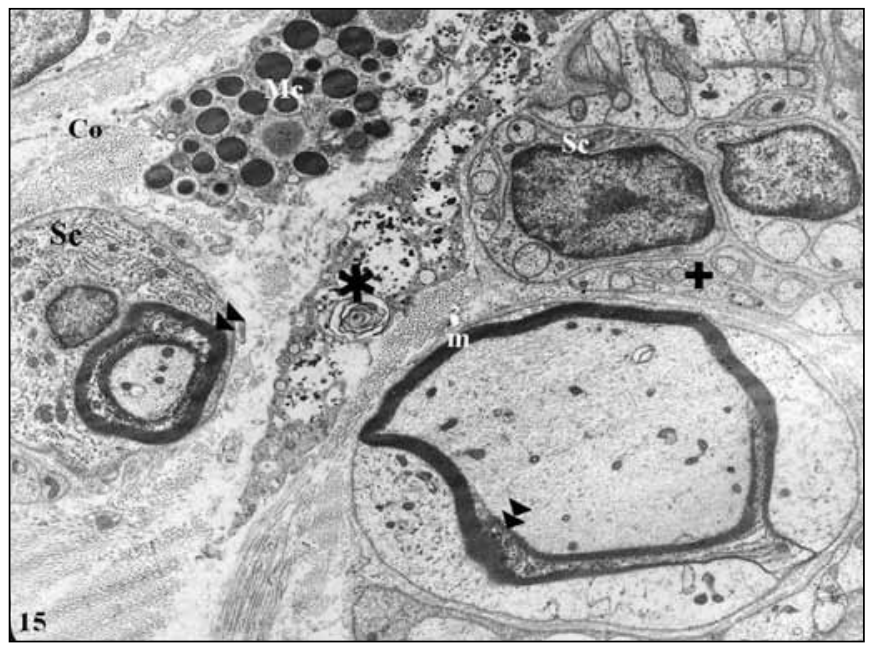

Figure 15: Higher magnification of sciatic nerve cross section from the trauma group. m; small myelinated nerve fibers, Sc; Schwann cell, $\gg$; duplication, Mc; Mast cell, *; macrophage with endosomes containing disintegrated myelin figures, +; unmyelinated fibers, Co; collagen fibers (Uranyl acetate \& Lead citrate, X4646).

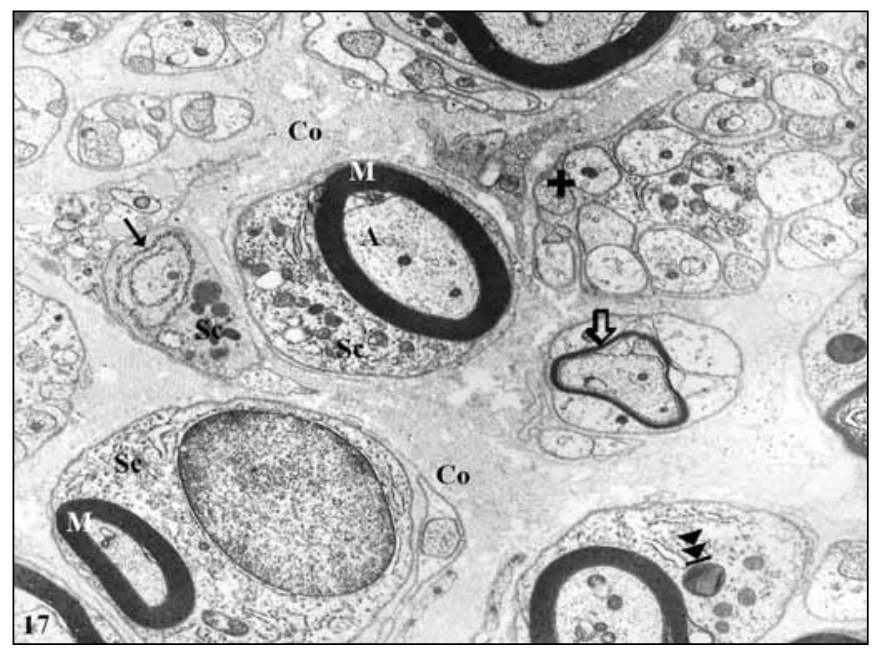

Figure 17: Sciatic nerve section from trauma+creatine group: M; myelinated nerve fibers, A; axon, Sc; Schwann cell, $\Rightarrow$; group newly forming myelin coats, $\rightarrow$; endoplasmic reticulum, $\longrightarrow$; remnants of phagocytic activity in Schwann cell, +; unmyelinated fibers, Co; collagen fibers (Uranyl acetate \& Lead citrate, X6000). 
Helvacioglu F. et al: Effect of Creatine on Peripheral Nerve Injury

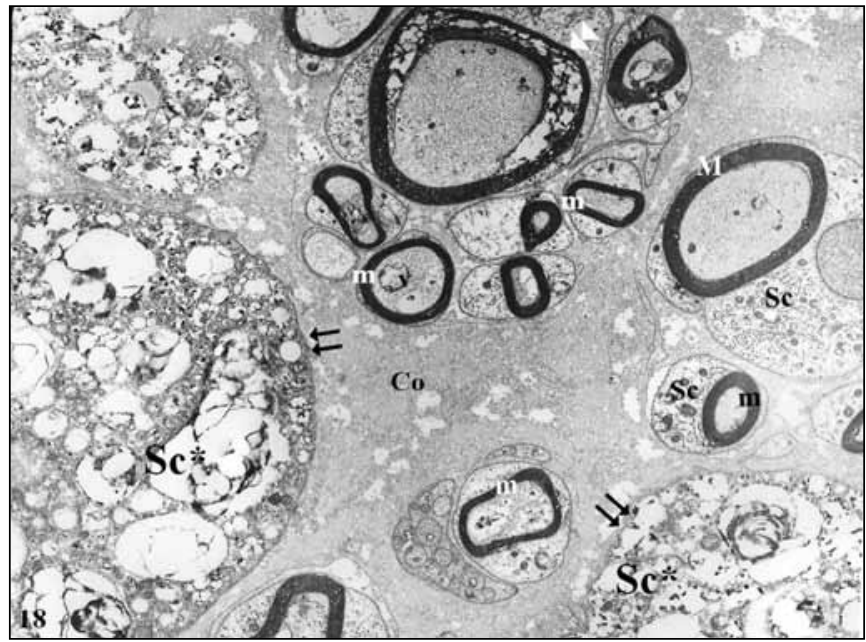

Figure 18: Sciatic nerve section from trauma+creatine group: $M$; large myelinated nerve fibers, $\mathrm{m}$; thin myelinated nerve fibers, Sc; Schwann cell, Sc*; disintegrated content of phagocytic Schwann cells, $\rightrightarrows$; external lamina, Co; collagen fibers (Uranyl acetate \& Lead citrate, X6000).

cell signalling directed pharmaceuticals, stem cell therapies and restorative/allograft-xenograft treatments, laser therapy etc. can be counted $(11,12,18,30,31,33,35,36)$. Such research is critical also for fighting against neurodegenerative disorders of the CNS as similar mechanisms possibly control the regeneration processes in both divisions of the nervous system. In other words, any effective approach to fiber regeneration in the peripheral nerves is worth studying in the CNS.

The most commonly used approach is supplementary therapy with several substances that are expected to influence this complex process positively as they are more easily available. Among these substances, melatonin, alpha-lipoic acid (23), EGCG (17), and several others like scr1 (33) can be mentioned. Creatine represents another commonly used supplement for this purpose recently, as valuable data have been obtained after wide usage of this agent for other purposes like body building or supporting the performance of the athletes (10). No harmful side effect of $2 \mathrm{mg} / \mathrm{kg}$ creatine supplement was reported yet though it was commonly used (23). Because it is one of the major endogenous substances for energy balance and regeneration or preventing degenerative processes that are both energy dependent, research has focused on the beneficial effects of creatine in nervous tissue disorders (32). However, we could not find any report on the effect of creatine on peripheral nerve injury in the literature. Thus, we planned to perform a comparative study on this issue using an experimental rat model with light and electron microscopic examinations.

Our comparative analysis results suggest a possible positive effect of creatine supplement on peripheral nerve regeneration as statistical analysis revealed significant differences between the Trauma and Trauma+creatine groups. Though our finding does not represent a miracle of regenerative support, beneficial usage of creatine is documented in the present study. Our extensive electron microscopic examinations also supported this view as presented in the results section. During our ultrastructural examinations, we also determined some figures of myelinophagy, a recently described form of autophagy, which is considered to be essential prior to the regeneration process. A number of other studies reported a similar effect of creatine supplement on protection from a variety of neurodegenerative diseases like Alzheimer, Parkinson, Huntington Chorea, and amyotrophic lateral sclerosis $(1,3,5,8,16,19,26,32)$. Results of a multi-center clinical study on the creatine effect in Parkinson disease also support the possible beneficial effect of creatine in such conditions (29). However there are also several studies reporting controversial findings as reviewed by Bender and Klopstock (6). Studies on the pathogenesis of neurodegenerative diseases like the one carried out in ndrg1 -/- mice (30), and plectin-mutated animals (4) outlined that the oxidative metabolism and inflammation are major counterparts of disease onset and development (31).

\section{CONCLUSION}

In ourview, creatine preserves its potential value in the treatment of such disorders as it is critical for the energy metabolism. We believe that further studies on the molecular mechanism of creatine supplements will be valuable to evaluate the potential therapeutic efficiency of this endogenous molecule.

\section{ACKNOWLEDGEMENT}

This study was funded by Baskent University after the approval of Baskent University Institutional Review Board and Ethics Committee (Project no: DA16/17). We thank Dr. Didem Bacanli for her contribution in the experimental procedure and we also thank Prof. Dr. Erhan Kiziltan for the development and improvement of the TT2D-BIAS software.

\section{REFERENCES}

1. Adhihetty PJ, Beal MF: Creatine and its potential therapeutic value for targeting cellular energy impairment in neurodegenerative diseases. Neuromolecular Med 10(4): 275290, 2008

2. Aksenov $M$, Aksenova $M$, Butterfield $D$, Markesbery $W$ : Oxidative modification of creatine kinase BB in Alzheimer's disease brain. J Neurochem 74: 2520-2527, 2000

3. Andres R, Ducray A, Schlattner U, Wallimann T, Widmer $\mathrm{H}$ : Functions and effects of creatine in the central nervous system. Brain Res Bull 76: 329-343, 2008

4. Bauer JW, Rouan F, Kofler B, Rezniczek GA, Kornacker I, Muss W, Hametner R, Klausegger A, Huber A, Pohla-Gubo G, Wiche G, Uitto J, Hintner $\mathrm{H}$ : A compound heterozygous one amino-acid insertion/nonsense mutation in the plectin gene causes epidermolysis bullosa simplex with plectin deficiency. Am J Pathol 158(2): 617-625, 2001

5. Beal M: Neuroprotective effects of creatine. Amino Acids 40: 1305-1313, 2011

6. Bender A, Klopstock T: Creatine for neuroprotection in neurodegenerative disease: End of story? Amino Acids 48(8):1929-1940, 2016

7. Benowitz L, Popovich P: Inflammation and axon regeneration. Curr Opin Neurol 24: 577-583, 2011 
8. Brewer G, Wallimann $\mathrm{T}$ : Protective effect of the energy precursor creatine against toxicity of glutamate and betaamyloid in rat hippocampal neurons. J Neurochem 74: 19681978, 2000

9. Bros H, Millward JM, Paul F, Niesner R, Infante-Duarte C: Oxidative damage to mitochondria at the nodes of Ranvier precedes axon degeneration in ex vivo transected axons. Exp Neurol 261: 127-135, 2014

10. Calfee R, Fadale P: Popular ergogenic drugs and supplements in young athletes. Pediatrics 117 (3):e577-e589, 2006

11. Câmara CN, Brito MV, Silveira EL, Silva DS, Simões VR, Pontes RW: Histological analysis of low-intensity laser therapy effects in peripheral nerve regeneration in Wistar rats. Acta Cir Bras 26(1): 12-18, 2011

12. Chen G, Zhang Z, Wei Z, Cheng Q, Li X, Li W, Duan S, Gu X: Lysosomal exocytosis in Schwann cells contributes to axon remyelination. Glia 60(2): 295-305, 2012

13. Chen P, Cescon M, Zuccolotto G, Nobbio L, Colombelli C, Filaferro M, Vitale G, Feltri ML, Bonaldo P: Collagen $\mathrm{VI}$ regulates peripheral nerve regeneration by modulating macrophage recruitment and polarization. Acta Neuropathol 129(1): 97-113, 2015

14. Chen P, Piao X, Bonaldo P: Role of macrophages in Wallerian degeneration and axonal regeneration after peripheral nerve injury. Acta Neuropathol 130(5): 605-618, 2015

15. Chomiak T, Hu B: What is the optimal value of the g-ratio for myelinated fibers in the rat CNS? A theoretical approach. PLoS One 4(11): e7754, 2009

16. Cunha MP, Martín-de-Saavedra MD, Romero A, Egea J, Ludka FK, Tasca Cl, Farina M, Rodrigues AL, López MG: Both creatine and its product phosphocreatine reduce oxidative stress and afford neuroprotection in an in vitro Parkinson's model. ASN Neuro 6(6) pii: 1759091414554945, 2014

17. Daglioglu E, Serdar Dike M, Kilinc K, Erdogan D, Take G, Ergungor F, Okay O, Biyikli Z: Neuroprotective effect of melatonin on experimental peripheral nerve injury: An electron microscopic and biochemical study. Cent Eur Neurosurg 70(3): 109-114, 2009

18. Dias FJ, Issa JP, Iyomasa MM, Coutinho-Netto J, Calzzani RA, lyomasa DM, Sousa LG, de Almeida SR, Cury DP, Watanabe IS: Application of a low level laser therapy and the purified protein from natural latex (Hevea brasiliensis) in the controlled crush injury of the sciatic nerve of rats: A morphological, quantitative, and ultrastructural study. Biomed Res Int 2013:597863, 2013

19. Fimognari C, Sestili P, Lenzi M, Cantelli-Forti G, Hrelia P: Protective effect of creatine against RNA damage. Mutat Res 670(1-2):59-67, 2009

20. Fu SY, Gordon T: The cellular and molecular basis of peripheral nerve regeneration. Mol Neurobiol 14(1-2):67-116, 1997

21. Gonzalez S, Berthelot J, Jiner J, Perrin-Tricaud C, Fernando R, Chrast R, Lenaers G, Tricaud N: Blocking mitochondrial calcium release in Schwann cells prevents demyelinating neuropathies. J Clin Invest 126(3):1023-1038, 2016

22. Guidi C, Potenza L, Sestili P, Martinelli C, Guescini M, Stocchi L, Zeppa S, Polidori E, Annibalini G, Stocchi V: Differential effect of creatine on oxidatively-injured mitochondrial and nuclear DNA. Biochim Biophys Acta 1780(1):16-26, 2008

23. Ipsiroglu OS, Stromberger C, Ilas J, Höger H, Mühl A, Stöckler Ipsiroglu S: Changes of tissue creatine concentrations upon oral supplementation of creatine-monohydrate in various animal species. Life Sci 69(15):1805-1815, 2001
24. Jung J, Jo HW, Kwon $H$, Jeong NY: ATP release through lysosomal exocytosis from peripheral nerves: The effect of lysosomal exocytosis on peripheral nerve degeneration and regeneration after nerve injury. Biomed Res Int 2014:936891, 2014

25. Kiziltan E, Helvacioglu F, Fidan PA, Dayanir D, Dagdeviren A: Periferik sinirde akson çapı ve miyelin kalınlıklarının değerlendirmesinde iki farklı görüntü analiz programının karşılaştırılması. Cell\&Tissue Biology Research Supplement 24-30 May. 111, 2014 (In Turkish)

26. Klopstock T, Elstner M, Bender A: Creatine in mouse models of neurodegeneration and aging. Amino Acids 40(5):12971303, 2011

27. Larocque D, Fragoso G, Huang J, Mushynski WE, Loignon M, Richard S, Almazan G: The QKI-6 and QKI-7 RNA binding proteins block proliferation and promote Schwann cell myelination. PLoS One 4(6): e5867, 2009

28. Lundborg G, Dahlin LB: Anatomy, function, and pathophysiology of peripheral nerves and nerve compression. Hand Clin 12(2): 185-193, 1996

29. NINDS NET-PD Investigators: A randomized, double-blind, futility clinical trial of creatine and minocycline in early Parkinson disease. Neurology 66, 664-671, 2006

30. Okuda T, Higashi Y, Kokame K, Tanaka C, Kondoh H, Miyata T: Ndrg1-deficient mice exhibit a progressive demyelinating disorder of peripheral nerves. Mol Cell Biol 24(9): 3949-3956, 2004

31. Park HT, Feltri ML: Rac1 GTPase controls myelination and demyelination. Bioarchitecture 1(3):110-113, 2011

32. Persky AM, Brazeau GA: Clinical pharmacology of the dietary supplement creatine monohydrate. Pharmacol Rev 53(2):161176, 2001

33. Ramaglia V, Wolterman R, de Kok M, Vigar MA, WagenaarBos I, King RH, Morgan BP, Baas F: Soluble complement receptor 1 protects the peripheral nerve from early axon loss after injury. Am J Pathol 172(4): 1043-1052, 2008

34. Rotshenker S: Wallerian degeneration: The innate-immune response to traumatic nerve injury. J Neuroinflammation 8:109, 2011

35. Saheb-Al-Zamani M, Yan Y, Farber S, Hunter D, Newton P, Wood M, Stewart S, Johnson P, Mackinnon S: Limited regeneration in long acellular nerve allografts is associated with increased Schwann cell senescence. Exp Neurol 247: 165-177, 2013

36. Sherman DL, Krols M, Wu LM, Grove M, Nave KA, Gangloff YG, Brophy PJ: Arrest of myelination and reduced axon growth when Schwann cells lack mTOR. J Neurosci 32(5):1817-1825, 2012

37. Silva LA, Tromm CB, Da Rosa G, Bom K, Luciano TF, Tuon T, De Souza CT, Pinho RA: Creatine supplementation does not decrease oxidative stress and inflammation in skeletal muscle after eccentric exercise. J Sports Sci 31(11):1164-1176, 2013

38. Webster $\mathrm{H}$ : Geometry of peripheral myelin sheaths during their formation and growth in rat sciatic nerves. J Cell Biol 48: 348-367, 1971

39. Williams P, Hall S: Chronic Wallerian degeneration - in-vivo and ultrastructural study. J Anat 109: 487-503, 1971

40. Yildirim A, Dalgic A, Divanlioglu D, Akdag R, Cetinalp N, Alagoz F, Helvacioglu F, Take G, Guvenc Y, Koksal I, Belen A: Biochemical and histopathological effects of catechin on experimental peripheral nerve injuries. Turk Neurosurg 25: 453-460, 2015 